\title{
Electron Transport in Paracoccus Halodenitrificans and the Role of Ubiquinone
}

Lawrence I. Hochstein and Sonja E. Cronin

June 1983

\section{LIBRARY COPY

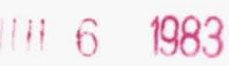

LANGLEY RESEARCH CENTER 


\section{Electron Transport in Paracoccus Halodenitrificans and the Role of Ubiquinone}

Lawrence I. Hochstein

Sonja E. Cronin, Ames Research Center, Moffett Field, California

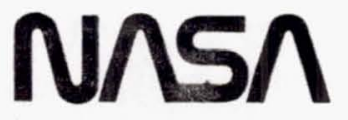

National Aeronautics and

Space Administration 
The membrane-bound NADH oxidase of Paracoccus halodenitrificans was inhibited by dicoumarol, 2-n-hepty1-4-hydroxyquinoline-N-oxide (HQNO), and exposure to ultraviolet light (at $366 \mathrm{~nm}$ ). When the membranes were extracted with $n$-pentane, $\mathrm{NADH}$ oxidase activity was lost. Partial restoration was achieved by adding the ubiquinone fraction extracted from the membranes. Succinate oxidation was not inhibited by dicoumarol or HQNO but was affected by ultraviolet irradiation or n-pentane extraction. However, the addition of the ubiquinone fraction to the n-pentane-extracted membranes did not restore enzyme activity. These observations suggested that reducing equivalents from succinate entered the respiratory chain on the oxygen side of the HQNO-sensitive site and probably did not proceed through a quinone. 
In an earlier study (22), exponentially growing cells of the moderately halophilic bacterium Paracoccus halodenitrificans were shown to maintain intracellular concentrations of potassium and sodium (with $\mathrm{K}^{+}>\mathrm{Na}^{+}$) that were independent of the extracellular concentrations of these ions. Cells taken from the maximum stationary phase were depleted with respect to $\mathrm{K}^{+}$and had accumulated $\mathrm{Na}^{+}$so that the intracellular concentrations of these ions approximated those found in the growth medium. These changes were also accompanied by changes in the activity of the membrane-bound NADH oxidase, suggesting a correlation between these ion fluxes and the activity of the respiratory chain. In order to gain a better understanding of these phenomena, a study of the electron transport system in $P$. halodenitrificans was initiated. The patterns of inhibition observed during NADH and succinate oxidation suggested that a menaquinone (MK) was associated with the oxidation of $\mathrm{NADH}$ while a ubiquinone (UQ) was involved in succinate oxidation. The presence of $M K$ and $U Q$ in the same organism is unusual and appears restricted to certain enteric bacteria $(2,25)$. Furthermore, the only quinone found in $\mathrm{P}$. halodenitrificans is UQ-9 (4). The results of the experiments described in this paper confirm that WQ-9 is the only detectable quinone in P. halodenitrificans and that NADH and succinate may not be oxidized through the same quinone pool.

\section{MATERIALS AND METHODS}

Growth of bacteria and preparation of membranes. P. halodenitrificans (ATCC 13511) was grown aerobically in a complex medium as previously described (22). Stationary-phase cells were harvested by 
centrifugation at $4,300 \times \mathrm{g}$ for $30 \mathrm{~min}$ at $4^{\circ} \mathrm{C}$ and immediately processed. The cells were suspended in $10 \mathrm{mM} \mathrm{N}$-2-hydroxyethylpiperazine-N'-2 ethane sulfonic acid (HEPES) $-500 \mathrm{mM} \mathrm{NaCl}$ buffer (pli 7.4) to a cellbuffer ratio of 0.25 (wt/v), passed through a cold French pressure cell operated at $15 \mathrm{kpsi}$ (103 $\mathrm{MPa})$, and the suspension centrifuged at $4,300 \times \mathrm{g}$ for $30 \mathrm{~min}$ at $4^{\circ} \mathrm{C}$. The supernatant was centrifuged at $175,000 \times \mathrm{g}$ for $60 \mathrm{~min}$ at $4^{\circ} \mathrm{C}$. The red gelatinous pellet was suspended in the HEPES-NaCl buffer and designated as the membrane fraction.

Assays. Oxygen consumption was measured polarographically using a Yellow Springs Model 53 Biological Oxygen Monitor and Model 5331 Oxygen Probe. The oxygen electrode was calibrated as described by Beechey and Ribbons ( 1 ) with membranes prepared from $P$. halodentrificans as the source of $\mathrm{NADH}$ oxidase. An air-saturated solution of the HEPES-NaCl buffer contained $225 \mathrm{nmol}$ of $\mathrm{O}_{2} \mathrm{mI}^{-1}$ at $30^{\circ} \mathrm{C}$.

$\mathrm{NADH}$ and succinate oxidase activities were assayed at $30^{\circ} \mathrm{C}$ in a total volume of $3 \mathrm{ml}$ in the presence of $30 \mu \mathrm{mol}$ of HEPES ( $\mathrm{pH} 7.4$ ) buffer and $1.5 \mathrm{mmol}$ of $\mathrm{NaCl}$. Depending on which oxidase activity was assayed, either $2.5 \mu \mathrm{mol}$ of $\mathrm{NADH}$ or $15 \mu \mathrm{mol}$ of succinate were added. The reaction was initiated by the addition of the membrane fraction, either $300 \mu g$ or $2 \mathrm{mg}$ of membrane protein, when $\mathrm{NADH}$ or succinate oxidase activities were assayed. A unit of oxidase activity was defined as that amount of enzyme catalyzing the consumption of $1 \mu \mathrm{mol}$ of $\mathrm{O}_{2} \mathrm{~min}^{-1}$, after correcting for any endogenous oxygen consumption. The dehydrogenases were assayed at room temperature spectrophotometrically at $410 \mathrm{~nm}$. To determine $\mathrm{NADH}$ dehydrogenase activity, the following additions were made in a total volume of $1 \mathrm{ml}$ : $10 \mu \mathrm{mol}$ HEPES ( $\mathrm{pH} 7.4$ ) buffer, 500 umol of 
$\mathrm{NaCl} ; 150 \mathrm{nmol}$ of $\mathrm{NADH} ; 1 \mu \mathrm{mol} \mathrm{K}_{3} \mathrm{Fe}(\mathrm{CN})_{6}$; and the membrane fraction (approximately $50 \mu \mathrm{g}$ of membrane protein). After first determining the nonenzymatic rate of ferricyanide reduction, the membrane fraction was added and the initial rate of reduction was determined. Succinate dehydrogenase was assayed in a reaction mixture containing the following additions in a total volume of $1 \mathrm{ml}$ : $60 \mu \mathrm{mol}$ of potassium phosphate buffer $(\mathrm{pH} 8.0) ; 10 \mu \mathrm{mol}$ of sodium succinate; $1 \mu \mathrm{mol}$ of $\mathrm{K}_{3} \mathrm{Fe}(\mathrm{CN})_{6}$; and the membrane fraction (about $250 \mu \mathrm{g}$ of membrane protein). A unit of dehydrogenase activity is that amount of enzyme catalyzing the reduction of $1 \mu \mathrm{mol}$ of ferricyanide $\mathrm{min}^{-1}$, using $1.0 \mathrm{mM}^{-1} \mathrm{~cm}^{-1}$ for the $\mathrm{mM}$ absorption coefficient. All activities were also corrected for any ferricyanide reduction that occurred in the absence of a substrate. In the oxidase and dehydrogenase assays, specific activity was defined as units mg protein ${ }^{-1}$.

Proteins were determined as described by Lowry et al. (17) using bovine serum albumin (Fraction V) as the standard. Sodium dodecylsulfate, at a final concentration of $0.1 \%$, was added to solubilize the membranes.

Photoinactivation studies. A model IL SC-1L PenRay Lamp (Ultraviolet Products, Inc.) was used for these studies. With this lamp, 97\% of the incident radiation occurred at $366 \mathrm{~nm}$. Appropriately diluted membranes were placed in a tube whose contents were protected from light and irradiated while stirring at $4^{\circ} \mathrm{C}$. Aliquots were periodically removed and assayed for the appropriate enzyme activities. Concurrently, 
a nonirradiated control was also assayed. No loss of any of the enzyme activities assayed was observed in the control.

Identification of quinones. Quinones were extracted with methanolacetone (14) or n-pentane (8), and purified by chromatography on acidwashed alumina (24). UQ was determined from the decrease in absorbance at $275 \mathrm{~nm}$ following the addition of $\mathrm{NaHB}_{4}$ using $12.5 \mathrm{mM}^{-1} \mathrm{~cm}^{-1}$ for the mM absorption coefficient (6).

The number of isoprenoid units was determined by mass spectrometry or reverse-phase thin-layer chromatography. Mass spectra were determined by Frank Church using a DuPont Model 21-491 Mass Spectrometer interfaced with a GCMS computer system, and the chromatographs were determined using $100 \mu \mathrm{m}$ precoated Avicel microcrystalline cellulose plates from EM Laboratories. The quinones were detected with leucomethylene blue (6). UQ standards were obtained from the Sigma Chemical Company with the exception of UQ-8, which was prepared from Escherichia coli (K-12) membranes in which it occurs as the principle UQ (7).

Incorporation studies. Lyophilized membranes were extracted nine times with n-pentane, using fresh $2-m l$ portions of the solvent for each extraction. The "depleted" membranes were dried for $1 \mathrm{hr}$ at room temperature in a rotary evaporator and "reconstituted" by addition of the quinone (dissolved in a minimal quantity of n-pentane) to a quinone-tomembrane protein ratio of $300 \mathrm{nmol}: \mathrm{mg}$. The suspension was stirred at $4^{\circ} \mathrm{C}$ for $30 \mathrm{~min}$, centrifuged at $17,300 \times \mathrm{g}$ for $30 \mathrm{~min}$ at $4^{\circ} \mathrm{C}$, and the supernatant discarded. The pellet was carefully rinsed with n-pentane 
and the residual pentane was removed by drying the membranes in a rotary evaporator for $1 \mathrm{hr}$ at room temperature. The quinones used in these experiments were either the UQ standards or the endogenous quinones. The latter were prepared from lyophilized membranes by methanol-acetore extraction (crude quinone) and subsequently purified by acid-alumina chromatography (purified quinone). All operations were carried out in subdued 1ight; fractions containing quinones were protected from light.

\section{RESULTS}

Inhibition of oxidase activities. The oxidation of NADH was sensitive to dicoumarol, suggesting that $\mathrm{NADH}$ was oxidized through an MK-dependent step; maximum inhibition of oxygen consumption ( $90 \%$ ) was observed when the dicoumarol concentration was approximately $50 \mu \mathrm{M}$, while $50 \%$ inhibition took place in the presence of about $5 \mu \mathrm{M}$ dicoumarol (Fig. 1a). NADH oxidation was also affected by 2-n-hepty1-4-hydroxyquinoline-N-oxide (HQNO), an inhibitor of electron transport at the level of cytochrome $b(3,13,15,19)$; maximum inhibition of oxygen consumption $(96 \%)$ occurred when the HQNO concentration was about $1.5 \mu \mathrm{M}$, while $50 \%$ inhibition was obtained at approximately $100 \mathrm{nM}$ inhibitor (Fig. 1b). Neither succinate oxidase nor $\mathrm{NADH}$ dehydrogenase activities were affected by these inhibitors even when, in the case of succinate oxidase, the concentrations of dicoumarol or HQNO were increased to $300 \mu \mathrm{M}$ and $12 \mu \mathrm{M}$, respectively.

Photoinactivation. The results of an experiment demonstrating the photosensitivity of $\mathrm{NADH}$ and succinate oxidases to 1ong-wavelength UV 
light are shown in Fig. 2a. NADH oxidase activity disappeared exponentially with a half-life of $18 \mathrm{~min}$, whereas $50 \%$ of the succinate oxidase activity disappeared after $40 \mathrm{~min}$. NADH and succinate dehydrogenase activities were also inactivated by $366 \mathrm{~nm}$ light (Fig. 2b). The NADH dehydrogenase was inactivated with a half-life of $7.5 \mathrm{hr}$, whereas succinate dehydrogenase inactivation took place with a halflife of $80 \mathrm{~min}$. Because of the inactivation of succinate dehydrogenase, it was unclear to what extent the photoinactivation of the dehydrogenase contributed to the loss of succinate oxidase activity.

The effect of solvent extraction. Extraction of membranes with either n-pentane or a methanol-acetone removed a UV-absorbing material. The maximum absorption of this material, located at $275 \mathrm{~nm}$, decreased and shifted to $290 \mathrm{~nm}$ upon the addition of $\mathrm{NaBH}_{4}$, which was suggestive of a UQ. No evidence for the characteristically complex spectrum of an MK (16) was observed in the membrane or in the high-speed supernatant fractions. When MK and UQ occur in the same microorganism, higher concentrations of the former are found in anaerobically grown cells $(20,25)$. Therefore, cells were grown anaerobically in the presence of $1 \% \mathrm{KNO}_{3}$ to increase the levels of $M K$, if any were present. The membrane and high speed supernatant fractions from anaerobically grown cells were examined spectrally, but the only material detected resembled that obtained from aerobically grown cells.

Extraction of the membrane fraction with n-pentane resulted in the loss of NADH oxidase activity. $\mathrm{NADH}$ oxidase activity in "depleted" membranes was partially restored by adding material extracted with 
either methanol-acetone or n-pentane. In addition, UQ-6, UQ-9, or UQ-10 partially restored $\mathrm{NADH}$ oxidase activity, each to about the same extent. No reactivation was observed when the vitamin $\mathrm{K}_{1}$ was added to the depleted membranes. An experiment illustrating reactivation with the endogenous quinone is shown in Table 1 . The lyophilized membranes were extracted with n-pentane, which resulted in the loss of about $93 \%$ of the $\mathrm{NADH}$ oxidase activity and $99 \%$ of the quinone (equivalent to removing $9.6 \mathrm{nmol}$ of $\mathrm{UQ} \times \mathrm{mg}$ membrane protein ${ }^{-1}$ ). NADH oxidase activity was partially restored by adding either the crude quinone fraction (obtained by methanol-acetone extraction) or the chromatographically purified quinone fraction. Following reactivation, NADH oxidase activity was inhibited by dicoumarol and HQNO (Table 1) to about the same extent as observed prior to depletion (Fig. 1). This indicated that the addition of the quinone fraction restored the respiratory chain rather than bypassing the quinone-depleted site.

Succinate oxidase activity was also affected by n-pentane extraction. However, depletion resulted in only a $28 \%$ loss of the initial succinate oxidase activity despite the extraction of $99 \%$ of the quinone (Table 1). No reactivation was observed when the crude quinone fraction was restored to the depleted membranes. Solvent extraction also caused a $36 \%$ loss of succinate dehydrogenase but none of the NADH dehydrogenase activity. As in the case of the photoinactivation experiments, the inactivation of succinate dehydrogenase could have accounted for the loss of succinate oxidase activity. 
Identification of the quinone. When a methanol-acetone extract of membranes was chromatographed on acid-washed alumina, the only quinone detected was eluted with $5 \%$ ethyl ether in petroleum ether. MK would have been eluted with $1 \%$ ethyl ether in petroleum ether. The absorption spectrum of the quinone was indistinguishable from the spectrum of authentic UQ-10 (6). The maxima before and after $\mathrm{NaBH}_{4}$ reduction were located at $275 \mathrm{~nm}$ and $290 \mathrm{~nm}$, respectively, and the ratio of the two maxima was 2.9 .

The length of the isoprenoid chain was identified by reverse-phase chromatography (Fig. 3). The quinone fraction extracted with methano1acetone (Fig. 3, position 2) and the material purified by alumina chromatography (Fig. 3, position 3) exhibited a single leucomethylene blue-oxidizing spot whose mobility was identical to that observed with authentic UQ-9 (Fig. 3, position 5). The mobility of the quinone obtained from anaerobically grown cells (Fig. 3, position 4) was also similar to UQ-9. The mass spectrum of the quinone exhibited prominent peaks at m/e 235 and 197, which are characteristic features of ubiquinones, and at $\mathrm{m} / \mathrm{e} 794$ and 796 , which correspond to the parent mass peaks for UQ-9 and its hydroquinone $(7,18)$. No peaks characteristic of UQ-8 and UQ-10 were observed at $\mathrm{m} / \mathrm{e} 726$ and 826 .

\section{DISCUSSION}

Ubiquinones occur in a variety of bacteria where they participate as hydrogen carriers linking the dehydrogenases (e.g., NADH and succinate) to the cytochrome portion of the respiratory chain (11). It is 
not clear how ubiquinones are organized in the electron transport chain; there is some question if ubiquinones exist as a mobile and homogeneous pool $(9,21)$.

The results described in this paper were consistent with the notion that $\mathrm{NADH}$ was oxidized through UQ-9. Although NADH oxidation was inhibited by dicoumarol, no MK was detected either spectrally or chromatographically. Dicoumarol also inhibits UQ-dependent reactions, such as the NADH-UQ segment of the mitochondrial respiratory chain (10) and the NADH oxidase of Aerobacter aerogenes, where the only quinone present is UQ-8 (12). Therefore, the inhibition of NADH oxidase activity by dicoumarol need not reflect an MK-dependent step in the oxidation of NADH. HQNO inhibits succinate oxidase activity at a site between UQ and oxygen (15). The absence of HQNO inhibition of succinate oxidase activity, and the apparent refractoriness of succinate oxidase activity to photoinactivation and solvent extraction, suggested that succinate was not oxidized through a UQ-dependent step. If we postulate that UQ did not exist as a mobile pool in P. halodenitrificans, then the differences observed in the oxidation of $\mathrm{NADH}$ and succinate can be reconciled with the notion that succinate is oxidized through UQ-9. Cox et a1. (5) proposed that in Escherichia coli, UQ associated with non-heme iron, occurred at two sites, bridged by cytochrome b. During NADH oxidation both quinones are reduced, whereas during the oxidation of D-lactate, only the UQ on the oxygen side of the cytochrome is reduced. Such a protein-associated UQ would not behave as if it were part of a pool. Trumpower (23) makes the point 
that if UQ were bound to a protein in the respiratory chain, such a quinone should have altered chemical and physical properties. Whether such binding would confer the kinds of differences we have observed is not clear.

At the present time, we cannot explain the behavior of succinate oxidation with respect to HQNO inhibition and quinone depletion. Studies are currently under way to determine if succinate is oxidized through UQ, or if UQ does not exist as a homogeneous and mobile pool. 


\section{LITERATURE CITED}

1. Beechey, R. B., and D. W. Ribbons. 1972. Oxygen electrode measurements, p. 25-53. In J. R. Norris and D. W. Ribbons (eds.) Methods in Microbiology. Vo1. 6B. Academic Press, Inc., New York.

2. Bishop, D. H. L., K. P. Pandya, and H. K. King. 1962. Ubiquinone and vitamin $\mathrm{K}$ in bacteria. Biochem. J. 83:606-614.

3. Burger, G. 1980. Binding and inhibitory effect of 2-hepty1-4hydroxyquinoline- $\mathrm{N}$-oxide in the presence of ubiquinone-3 in Saccharomyces cerevisiae. Eur. J. Biochem. 106,661-665.

4. Collins, M. D., H. N. M. Ross, B. J. Tindall, and W. D. Grant. 1981. Distribution of isoprenoid quinones in halophilic bacteria. J. App1. Bacteriol. 50:559-565.

5. Cox, G. B., N. A. Newton, F. Gibson, A. M. Snoswe11, and J. A. Hamilton. 1970. The function of ubiquinone in Escherichia coli. Biochem. J. 117:551-562.

6. Crane, F. I., and R. Barr. 1971. Determination of ubiquinones. Methods Enzymo1. XVIII (Part C):137-169.

7. Daves, G. D., R. F. Muraca, J. S. Whittick, P. Friis, and K. Folkers. 1967. Discovery of ubiquinones $-1,-2,-3$ and -4 and the nature of biosynthetic isoprenylation: Biochemistry $\underset{\sim}{6}: 2861-2866$.

8. Ernster, L., I. Y. Lee, B. Norling, and B. Persson. 1969. Studies with ubiquinol-depleted submitochondrial particles. Essentiality of ubiquinone for the interaction of succinate dehydrogenase, NADH dehydrogenase, and cytochrome B. Eur. J. Biochem. 9:299-310. 
9. Ferguson, S. J. 1982. Aspects of the control and organization of bacterial electron transport. Biochem. Soc. Trans. 10:198-200.

10. Hatefi, Y., A. G. Haavik, and P. Jurtshuk. 1960. Studies on the electron transport system. XXXII-Reduction of coenzyme Q by DPNH. Biochem. Biophys. Res. Commun. $\underset{\sim}{3}: 281-286$.

11. Jones, C. W. 1977. Aerobic respiratory systems in bacteria. In B. A. Haddock and W. A. Hamilton (eds.), Microbial energetics, Society for General Microbiology Symposium. 27:23-59. Cambridge University Press, London.

12. Knook, D. L., H. F. Kauffman, and J. Van 'T Riet. 1974. Different effects of 2-n-hepty1-4-hydroxyquinoline-N-oxide on oxygen and nitrate respiration in Klebsiella aerogenes. Arch. Biochem. Biophys. 165:449-455.

13. Knook, D. L., and R. J. Planta. 1971. Function of ubiquinone in electron transport from reduced nicotinamide adenine dinucleotide to nitrate and oxygen in Aerobacter aerogenes. J. Bacteriol. $105: 483-485$.

14. Kroeger, A., and V. Dadak. 1969. On the role of quinones in bacterial electron transport. The respiratory system of Bacillus megaterium. Eur. J. Biochem. 11:328-340.

15. Kroeger, A., V. Dadak, M. Klingenberg, and F. Diemer. 1971. On the role of quinones in bacterial electron transport. Differential roles of ubiquinone and menaquinone in Proteus rettgeri. Eur. J. Biochem. 21:322-333. 
16. Lester, R. L., D. C. White, and S. L. Smith. 1964. The 2-desmethyl vitamin $\mathrm{K}_{2}$ 's. A new group of naphthoquinones isolated from hemophillus parainfluenzae. Biochemistry $\underset{\sim}{3: 949-954 .}$

17. Lowry, 0. H., N. J. Rosebrough, A. L. Farr, and R. J. Randall.

1951. Protein measurements with the Folin phenol reagent. J. Biol. Chem. 193:265-275.

18. Muraca, R. F., J. S. Whittick, G. D. Daves, P. Friis, and K. Folkers. 1967. Mass spectra of ubiquinones and ubiquinols. J. Amer. Chem. Soc. 89:1500-1503.

19. Papa, S., G. Izzo, and F. Guerrieri. 1982. On the inhibition of the $b-c l$ segment on the mitochondrial respiratory chain by quinone analogues and hydroxyquinoline derivatives. FEBS Lett. $145: 93-98$.

20. Polglase, W. J., W. T. Pun, and J. Withaar. 1966. Lipoquinones of Escherichia coli. Biochim. Biophys. Acta 118:425-426.

21. Rich, P. R. 1981. A general model for the equilibration of quinone pools with their biological donors and acceptors in membranebound electron transfer chains. FEBS Lett. 130:173-178.

22. Sadler, M. H., M. McAninch, R. Alico, and L. I. Hochstein. 1980. The intracellular $\mathrm{Na}^{+}$and $\mathrm{K}^{+}$composition of the moderately halophilic bacterium, Paracoccus halodenitrificans. Canad. J. Microbiol. 26:496-502.

23. Trumpower, B. L. 1981. New concepts on the role of ubiquinone in the mitochondrial respiratory chain. J. Bioenerg. Biomembr. $13: 1-24$. 
24. Whistance, G. R., J. F. Dillon, and D. R. Threlfall. 1969. The nature, intergenic distribution and biosynthesis of isoprenoid quinones and phenols in gram-negative bacteria. Biochem. J. $111: 461-472$.

25. Whistance, G. R., and D. R. Threlfall. 1968. Effect of anaerobiosis on the concentrations of demethylmenaquinone, menaquinone and ubiquinone in Escherichia freundii, Proteus mirabilis, and Aeromonas punctata. Biochem. J. 108:505-507. 
TABLE 1. Restoration of oxidase activities following $\underline{\text { extraction with }} \mathrm{n}$-pentane $^{\alpha}$

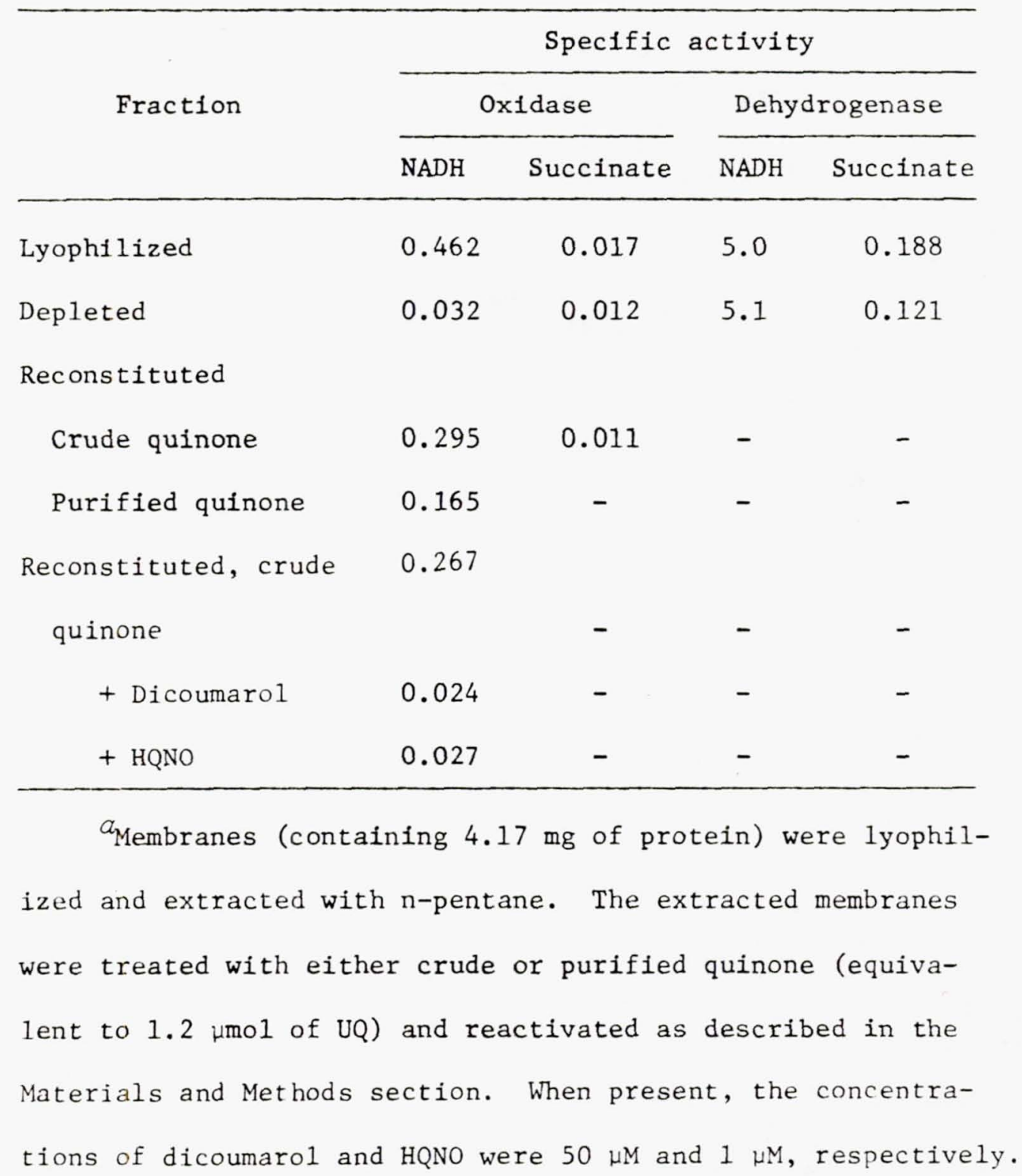




\section{Figure Captions}

FIG. 1. Inhibition of NADH oxidase activity. $100 \%$ maximum sp act is equivalent to 0.391 (A) and 0.417 (B). In these experiments $280 \mu \mathrm{g}$ of membrane protein was added. When NADH oxidase activity was assayed in the presence of $10 \mu 1$ of ethanol (the solvent used to dissolve HQNO and the quantity added at each HQNO concentration), a slight stimulation of NADH oxidase activity was observed. This is reflected in the higher specific activity of the membrane fraction in (B).

FIG. 2. Photoinactivation of $\mathrm{NADH}$ and succinate oxidation. Membranes were diluted in $10 \mathrm{mM}$ HEPES-500 $\mathrm{mM} \mathrm{NaCl}$ buffer ( $\mathrm{pH} 7.4$ ) to give a final protein concentration of $2 \mathrm{mg} \mathrm{m}^{-1}$, and $7 \mathrm{ml}$ of the membrane suspension were irradiated at $4^{\circ} \mathrm{C}$. Aliquots were periodically removed, and assayed for $\mathrm{NADH}(0)$ and succinate $(\bullet)$ oxidase activities (A) and dehydrogenase activities (B). The initial specific activities for (A) were 0.239 and 0.033 , respectively; those for (B) were 2.6 and 0.15 , respectively.

FIG. 3. Reverse phase chromatography of ubiquinones. The following materials were chromatogrammed: (1) a standard mixture containing UQ-6, UQ-7, UQ-8, UQ-9, and UQ-10; (2) the crude quinone fraction, obtained by methanol-acetone extraction; (3) the quinone fraction after purification by acid-alumina chromatography; (4) the crude quinone fraction from anaerobically grown cells; and (5) authentic UQ-9. 


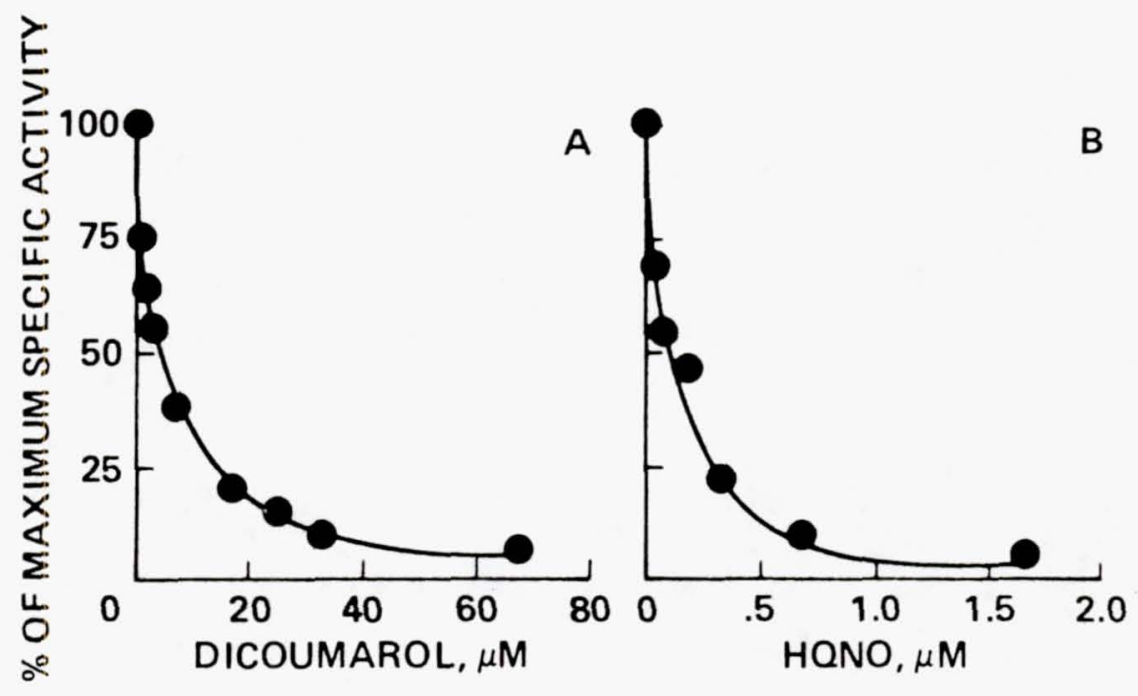

Fig. 1 


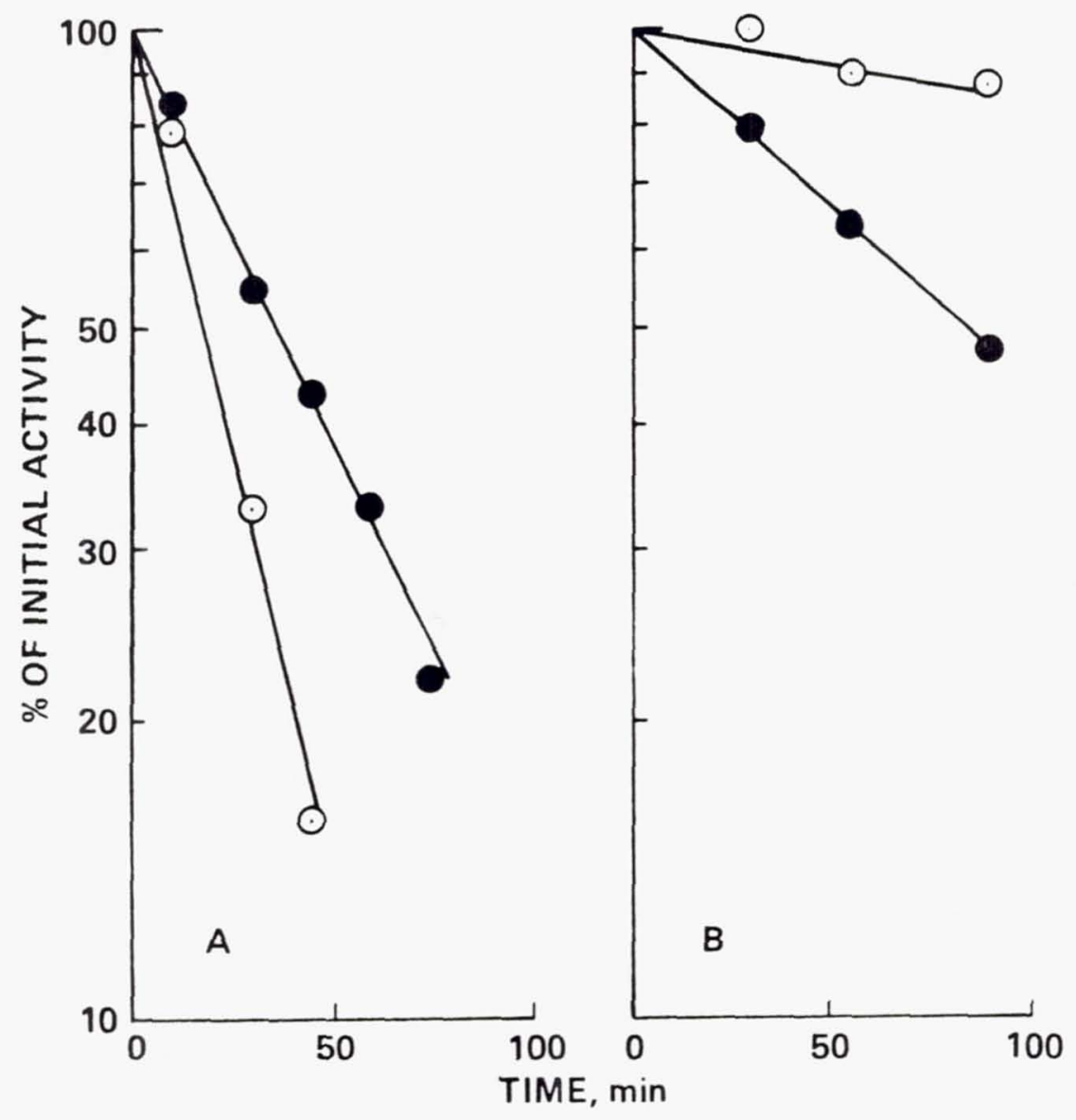

Fig. 2 


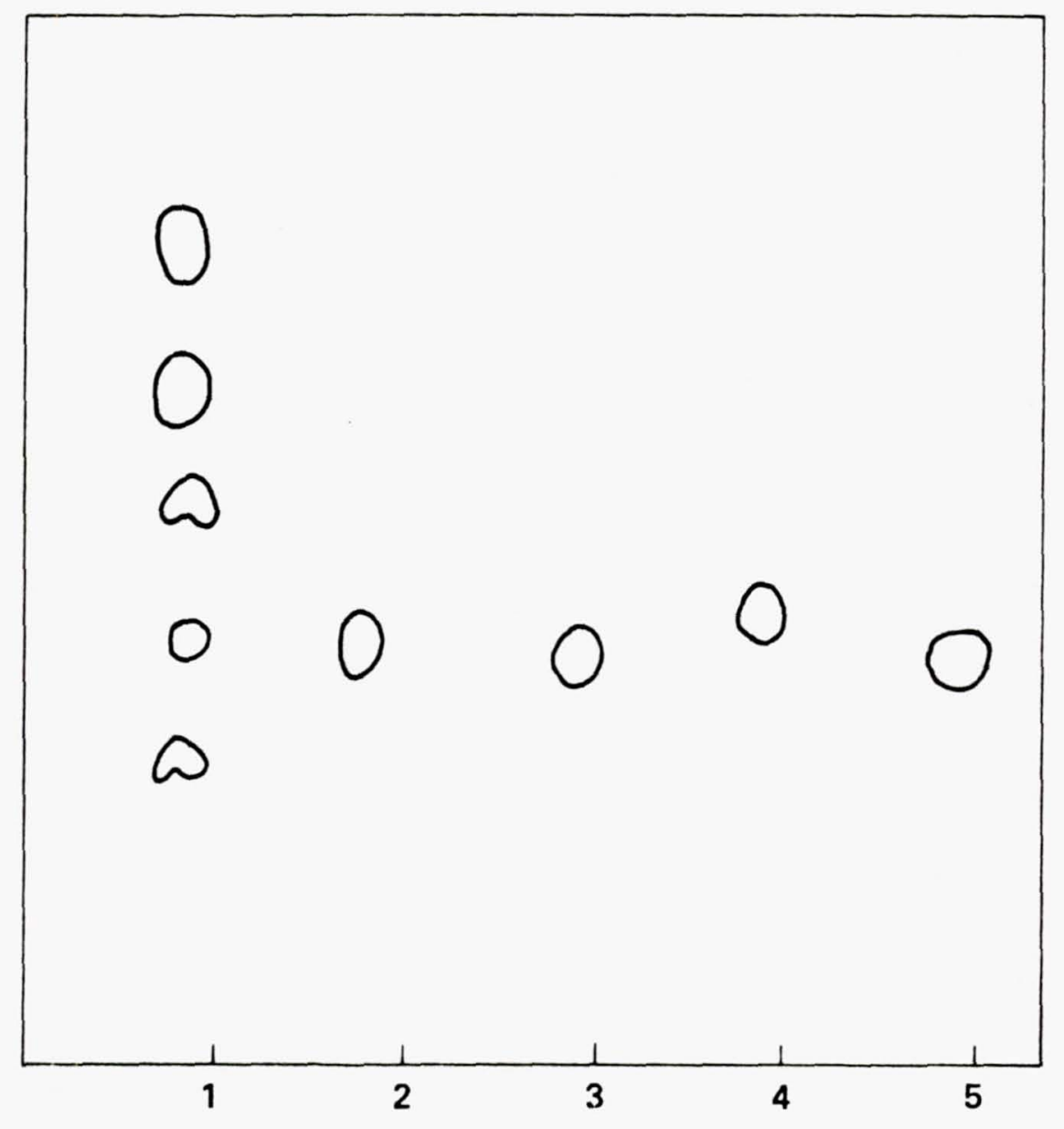

Fig. 3 


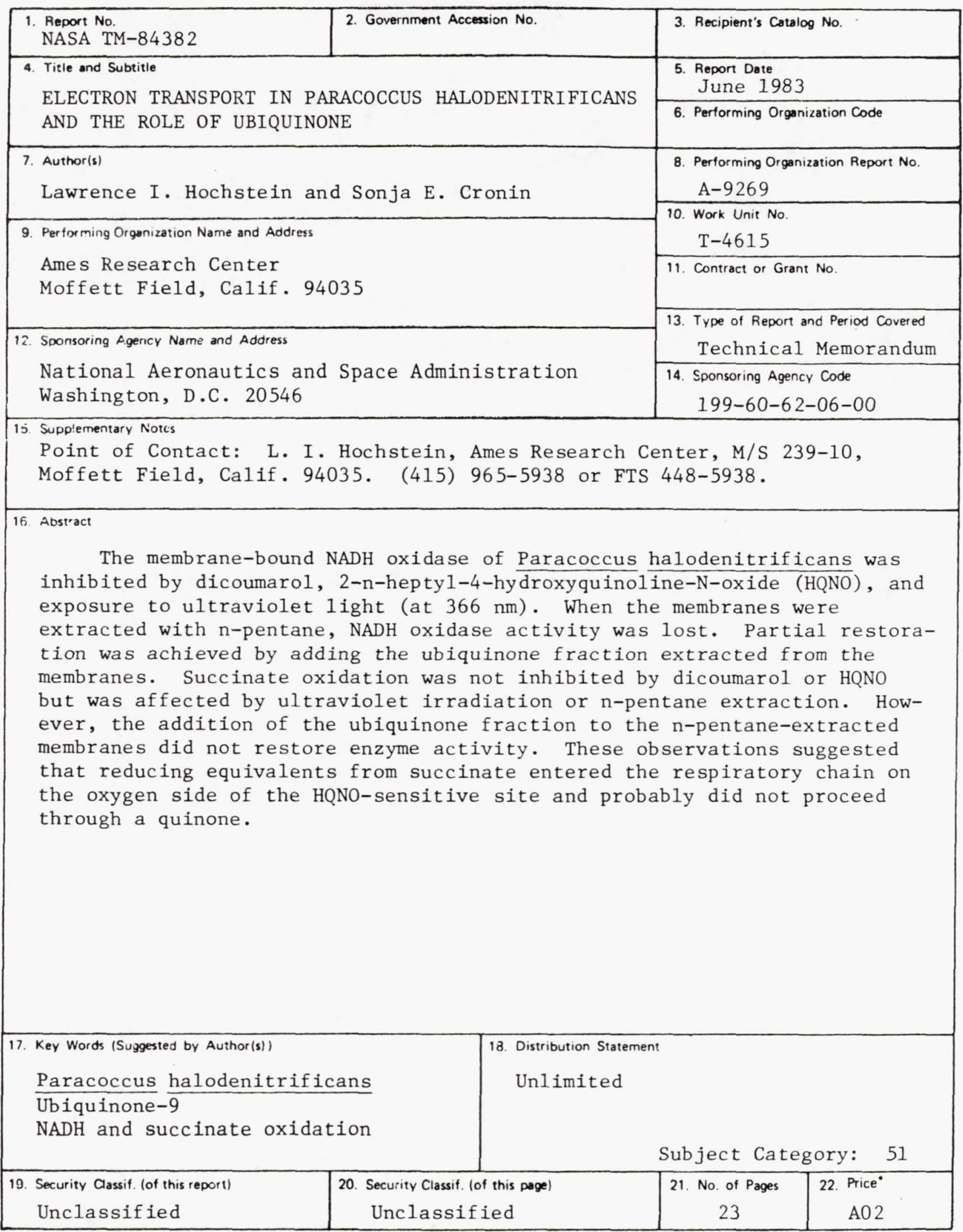

- For sale by the National Technical Information Service, Springfield, Virginia 22161 